\title{
Hoverwing Araçlarda Kaldırma Sistemi için Gövde Tasarımı ve
} Analizi

\author{
Ömer Çağdaş Çınkır ${ }^{1 *}$, Tugay Öztürk ${ }^{2}$, Satılmış Ürgün ${ }^{3}$, Sinan Fidan $^{4}$ \\ 1* Kocaeli Üniversitesi, Fen Bilimleri Enstitüsü, Havacılık Bilimi ve Teknolojileri Bölümü, Kocaeli, Türkiye, (ORCID: 0000-0002-4610-1267), \\ o.cagdascinkir@gmail.com \\ ${ }^{2}$ Kocaeli Üniversitesi, Fen Bilimleri Enstitüsü, Havacılık Bilimi ve Teknolojileri Bölümü, Kocaeli, Türkiye, (ORCID: 0000-0002-2576-3974), \\ tugayoztrk139@gmail.com \\ ${ }^{3}$ Kocaeli Üniversitesi, Havacılık ve Uzay Bilimleri Fakültesi, Havacılık Bilim ve Teknolojileri Bölümü, Kocaeli, Türkiye, (ORCID: 0000-0003-3889-6909), \\ urgun@kocaeli.edu.tr \\ ${ }^{4}$ Kocaeli Üniversitesi, Havacılık ve Uzay Bilimleri Fakültesi, Havacıllk Bilim ve Teknolojileri Bölümü, Kocaeli, Türkiye, (ORCID: 0000-0003-4385-4981), \\ sfidan@kocaeli.edu.tr
}

(İlk Geliş Tarihi 3 Haziran 2021 ve Kabul Tarihi 13 Eylül 2021)

(DOI: $10.31590 /$ ejosat.947307)

ATIF/REFERENCE: Çınkır, Ö.Ç., Öztürk, T., Ürgün, S. \& Fidan, S. (2021). Hoverwing Araçlarda Kaldırma Sistemi için Gövde Tasarımı ve Analizi. Avrupa Bilim ve Teknoloji Dergisi, (27), 526-531.

$\ddot{O} \mathbf{z}$

Hava yastıklı taşıtlar hem kara hem de su operasyonlarında kullanılmaya müsait amfibi taşıtlardır. Bu taşıtlar çoğu hava aracı gibi havalanabilmek için kanatlara ihtiyaç duyarken, aynı zamanda gövdesinin alt kısmından basınçlı havayı koşullandırarak yukarı yönde kuvvet oluşturur. Yönlendirilmiş hava ve aracın ağırlığı sebebiyle gövde altında basınçlı bir hava bölgesi oluşur (Air cushion). Böylece hoverwing kum, çakıl, çamur ve su üstünde uçak gibi uçarken aynı zamanda da bot gibi suda yüzdürülebilir. Bu çalışmada üretilmesine karar verilen bir howerwing taşıtın gövdesine eklenecek olan kaldırma sistem tasarımı ele alınmıştır. Bu süreç esnasında hull Solidworks'de çizilmiş, Ansys Fluent'te akış analizleri yapılmıştır. Bu analizler doğrultusunda optimum inlet açısının "realizable k-e" türbülans modellemesi kullanılarak $22^{0}$ olduğu saptanmıştır. Böylece gövde çıkışlarından etek girişlerine laminer ve yeterli basınçta hava dağıtımı yapılırken bu havayı sağlayacak inlet, aracın genel tasarımına uygun bir şekilde tasarlanmıştır.

Anahtar Kelimeler: ANSYS, FLUENT, H.A.D., Hoverwing, Hava Yastıklama, Realizable k-e.

\section{Fusulage Design and Analysis for Lifting System in Hoverwing Vehicles}

\begin{abstract}
Air cushion vehicles are amphibious vehicles suitable for use in both land and water operations. While these vehicles, like most aircraft, need wings to take off, they also create an upward force by conditioning the compressed air from the lower part of the body. Due to the directed air and the weight of the vehicle, a compressed air zone is created under the body (air cushion). Thus, the hoverwing can fly like an airplane on sand, gravel, mud, and water while at the same time floating in the water like a boat. In this study, the design of the lifting system to be added to the body of a howerwing vehicle decided to be produced is discussed. During this process, hull was drawn in Solidworks and flow analysis was made in Ansys Fluent. In line with these analyzes, it was determined that the optimum inlet angle was $22^{\circ}$ by using "realizable k-e" turbulence modeling. Thus, while air is distributed from the body exits to the skirt inlets with laminar and sufficient pressure, the inlet that will provide this air has been designed in accordance with the general design of the vehicle.
\end{abstract}

Keywords: Air Cushion, ANSYS, CFD, FLUENT, Hoverwing, Realizable k-e.

* Sorumlu Yazar: o.cagdascinkir@gmail.com 


\section{Giriş}

Hoverwing taşıtlar hava yastıklaması prensibinden faydalanan araçlardır. Bu sayede karada, suda ve çamurlu yüzeylerde operasyon yürütebilirler. Howerwing araçlar, itki ve kaldırma olmak üzere iki temel kuvvet sayesinde hareket ederler. Kaldırma kuvveti sadece kanatlar tarafindan üretilmez, buna yardımc olarak kaldırma sistemi kullanılır(Tiwari, 2015). Kaldırma sistemi sayesinde gövde ve yüzey arasında atmosferik basınçtan daha yüksek basınca sahip bir alan oluşturulur. Yastıklama diye tabir edilen bu basınçlandırılmış bölgedeki hava, gövde ile su yüzeyi arasında sürtünmeyi azaltarak suyun taşıta uygulamış olduğu hidrodinamik kuvveti minimize eder. Ayrıca basınçlı hava gövdeyi saran bir etek yapısının içinde olduğu için taşıt küçük engeller üzerinden hasar almadan operasyon yürütülmesine olanak sağlar(Durgawale, Mali, Patil, Raut ve Suryawanshi, 2017).

Yer etkisi olgusu ilk olarak 1920'li yıllarda araştırılmaya başlanmıştır. İlk yer etkili taşıt olarak adlandırılan "wing-ram" Finli mühendis T. Kaario tarafından 1935 yılında üretilmiştir. Fakat stabilite sorunu aşılamamıştır. Pratikte ilk çalışan yer etkili taşıt, diğer adıyla Ekoroplan Rus mühendis R. Alexeyev tarafından tasarlanmıştır. 510 ton ağırlığındaki KM (Hazar Denizi Canavarı) 1960'lı yıllarda üretilmiştir. Aynı yıllarda Alman ve Amerikan mühendisler yer etkili taşıt çalışmaları geliştirmişlerdir. 1980'lerden günümüze çok sayıda eğlence ve bireysel amaçlı yer etkili taşı tasarlansa da ticarileşme süreçlerini henüz tamamlayamamışlardır(Martin, Vehicle, Williams ve Wunderlin, 2016).

Hull yapısı havayı yönlendirmede yardımcı bir yapısaldır. Hull yapısının birçok işlevi mevcuttur. Genellikle kutu şeklindedir ve taşıtın ortasına yerleştirildiğinden taşıtın yüzme kabiliyetini artırır. Aynı zamanda rijit yapıları sayesinde diğer parça ve cihazların montajına olanak sağlarlarken, yük ve yolcu dağılımında ana yapısallara destek olur. Yaygın olarak kullanılan hull yapıları kutu şeklindedir. Bu sayede kaynaklı veya perçinli üretimi sayesinde sızdırmazlığı sağlanabilir (Martin, Vehicle, Williams ve Wunderlin, 2016; Abele ve Brown, 1977).

Küçük ölçekli Hoverwing taşıtlarda etek yapısı hull dan çıkan dairesel delikler sayesinde beslenir. Yapısal yük ve aracın rijitliği göz önüne alındığında küçük ölçekli hoverwing taşıtlarda kompozit hull yapısı uygulanabilir. $\mathrm{Bu}$ sayede elde edilen tasarım esnekliğiyle hull yapısı hava yönlendirmede daha efektif bir şekilde kullanılabilir. $\mathrm{Bu}$ çalışmada bu konuya değinilmiştir(Sun ve Xia, 2002).

Rüzgar tünelleri, hava akışının bir katı etrafındaki hareketini incelemek ve ölçmek için rüzgarın fanlar tarafından veya basınçlı hava ile üretildiği tesislerdir (dairesel, eliptik veya dikdörtgen tüneller vb.). Test bölümü, katının çalışıldığı çevrimin parçasıdır. On dokuzuncu yüzyılın sonlarında icat edilen bu aerodinamik laboratuvarlar, yirminci yüzyılın başlarında faaliyete geçmiştir. Yöntem, 1687'de Isaac Newton tarafından dile getirilen görelilik ilkesine dayanmaktadır.

Günümüzde deneysel uygulama düzeneklerinin pahalı ve zaman alıcı olmasından dolayı maliyeti azaltıp zamandan kazanmak için hızlı bir şekilde ve aynı zamanda doğru olarak çözümleyebilen bilgisayar programları geliştirilmiştir. Hesaplamalı akışkanlar dinamiği (HAD) yöntemleri akışı yöneten denklemleri nümerik analizlere ve sayısal algoritmalara dönüştürerek ve güçlü bilgisayarlar kullanarak çözümlenmesini e-ISSN: 2148-2683 sağlayan modern yöntemlerdir. Hesaplamalı Akışkanlar Dinamiği (HAD) tekniklerinin endüstriyel ve endüstriyel olmayan alanlarda kullanımı oldukça yaygındır. Bunların en önemli örnekleri havacılık, savunma ve otomotiv endüstrisidir. Aynı zamanda belirlenen koşullar ve senaryo çerçevesinde herhangi bir anda herhangi bir noktadaki akışkanı gözlemleme ve inceleme imkânı sunmaktadır (Bhaskaran ve Collins, 2002).

Literatürde hava yastıklamalı araçlarla alakalı çalışmalar olsa da Howerwing gibi hem hava yastıklamalı hem de kanatlı tasarım, uçuş stabilitesi ve ticari kaygılardan dolayı fazla yaygınlaşmamıştır. Yine de hava yastıklaması ve yer etkisi için hovercraft'larda yapılan çalışmalar ve deneyimler bu çalışmaya 1 şık tutmuştur. Hull'un kutucuk şeklindeki yapısı ve bizim istediğimiz stabil ve aynı zamanda eşit basınçlı hava çıkışları bize analiz benzerliklerini kullanma imkanı sağlamıştır. Ancak literatüre baktığımızda Yun ve Bliault'un ders kitabı temel bir referanstır(Sun ve Xia, 2002). HAD analizleri temelde, içeri akış ve dişarı akış olarak ikiye ayrılır. İçeri veya dişarı akış olma durumuna göre yapılacak olan HAD analizinin katı duvar kısımları belirlenir ve ona göre analize uygun sınır şartları belirlenir. Böylelikle doğru akış denklemleri kullanılabilir (Dal, Özkaya ve Şahin, 2020; Kaya ve Özcan, 2013). Bal'1n (2019) yapmış olduğu çalışmada k- $\varepsilon$, HAD analizleri ve Akdemir, Edis, Öztürk ve Ülger'in (2012) yaptıkları çalışmalar hull yapısının iç hacmindeki içeri akışın üç boyutlu modellenmesine örnek teşkil etmiştir. "Soğuk Hava Depolarında Ortam Koşullarının Hesaplamalı Akışkanlar Dinamiği (CFD) ile Modellenmesi" isimli çalışmada hull yapısının modellenmesi ve analizi yapılmıştır (Sun ve Xia, 2002). Hovercraft tasarımında genel geliştirme sürecini takip edildiği ve analizlerini yapıldığ çalışmalar bulunmaktadır (Anant, Bhardwaj, Bohidar, Jaiswal ve Sen, 2014; Sun ve Xia, 2002).

$\mathrm{Bu}$ çalışmada hull yapısının kendinden beklenen basınçlı havayı düz uçuş sırasında aracın dengesini bozmayacak şekilde homojen olarak hull içerisinde dağıtılması ve aynı zamanda hava yastıklama etkisini yaratması için analizler yapılmıştır. 00 giriş açısından başlanarak 300 ye kadar giriş açısı değiştirilerek optimum giriş açısı elde edilmeye çalışılmıştır. Aynı zamanda giriş açısı değiştirilerek yapılan bu analizlerde havanın hull yapısı içerisinde ve çıkış alıklarında en homojen ve türbülanssız olarak yayılımı elde edilmeye çalışılmıştır. Çalışma için en uygun analiz metodunun seçimi Şekil 2'deki HAD akış fizikleri blok diyagramı takip edilerek oldukça geniş kullanıma sahip ticari yazılım olan ANSYS FLUENT kullanılmıştır. Yazılımın bize sunduğu denklem paketlerinden elimizdeki geometri için gerçeğe en yakın sonuçları veren "realizable k-e" türbülans modellemesi tercih edilmiştir. Yapılan bu analizler sonucunda havanın optimum geliş açısının $22^{0}$ olduğu elde edilmiştir. Buna müteakip hull içinde havanın duvarcıklar yardımıyla yönlendirilmesinin de faydalı olduğu saptanmıştır.

\subsection{Hesaplamalı Akışkanlar Dinamiğinin Uygulanması}

Hesaplamalı akışkanlar dinamiği analizini gerçekleştirmek için ilk önce problemi matematiksel olarak ifade etmek ve bilimsel etmek gerekir. Son olarak bilgisayar analiz programı tarafindan dikte edilen hesaplamaları yapar.

Prensip olarak bir simülasyon gerçekleştirmek için üç farklı ana görev yapılmalıdır. Bunlar; ön işlem süreci, işlem süreci ve 
son işlem sürecidir. Bu süreçler ve ara basamakları Şekil 1'de akış şeması olarak verilmiştir (Liu, Tu ve Yeoh, 2018).

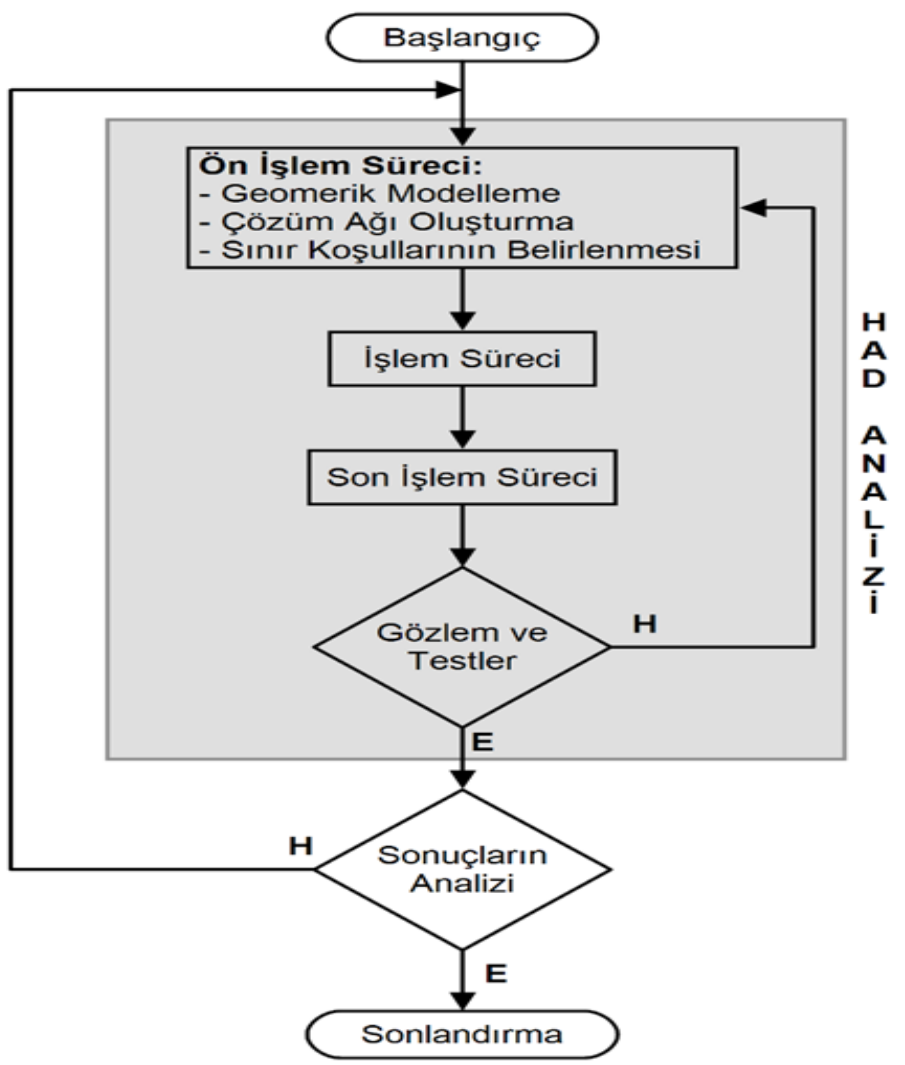

Şekil 1.HAD Analizi Akış Şeması

\subsection{1. Ön İşlem Süreci}

$\mathrm{Bu}$ çalışmada ön işlem süreci sayısal çözüm aşamasıdır. Bu aşama, problem hakkında düşünmeyi, çözüm ağı oluşturmayı ve hesaplama modeli oluşturmayı içerir.

Problem hakkında düşünmek HAD kullanımının ilk adımıdır. Böylece problemin çözümüne dair uygulayabileceğimiz metotlar ve matematiksel modellemeleri ön görebiliriz. CAD programlarıyla modellenen geometri HAD programına entegre edilir. Bundan sonra geometri çözüm ağı ile HAD programının hesaplama yapabileceği bir zemin oluşturulur. Çözüm ağı oluşturma işlemi tamamlandıktan sonra problemin sınır koşulları belirlenir. Bu koşullara akış parametreleri ve fiziksel özellikleri de dahildir. İyi bir analiz için bunların yanı sıra örgü yoğunluğu ve örgü sayısı kritik bir öneme sahiptir.

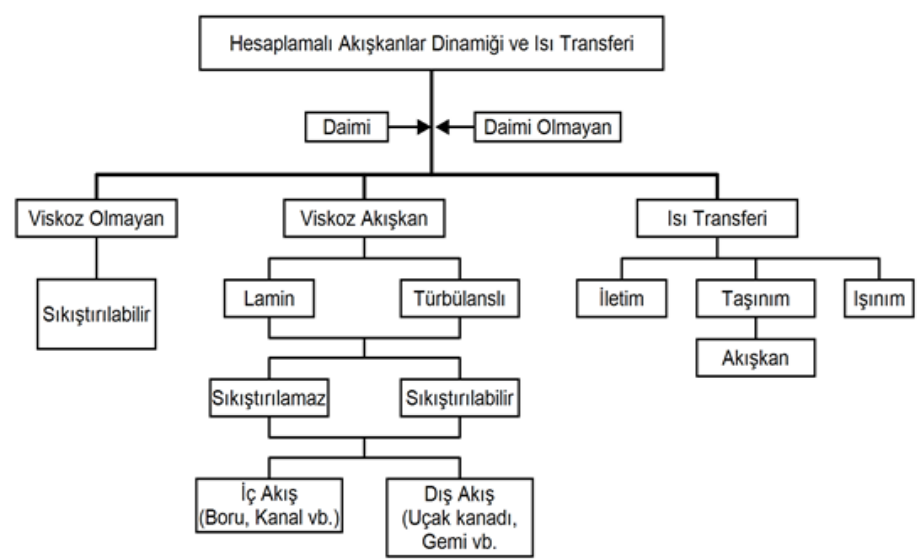

Şekil 2. HAD akış fizikleri blok diyagramı (Launder ve Sharma, 1974).
HAD akış diyagramı değerlendirilirken, en uygun metodu seçebilmesi için öncelikle akış fiziklerinin iyi bir şekilde tamamlanması gereklidir. Bunun için birinci adım akışımızın daimi mi yoksa geçici mi olduğuna karar vermektir. İkinci adım akışın, viskoz olmayan akışkan mı viskoz akışkan mı olduğunu belirlemektir. Bu çalışmada hava viskoz akışkan olduğu için ve Reynold katsayımız 105 den daha büyük olduğu için türbülanslı akış kategorisine dahil olmaktadır. Türbülanslı akışlar sıkıştırılabilir ve sıkıştırılamaz akış olmak üzere ikiye ayrılmaktadır. $\mathrm{Bu}$ çalışmada hava hızı 0.064 Mach dir. 0.3 Mach'a kadar hıza sahip akışkanlar sıkıştırılamaz kabul edildiği için bu çalışmadaki akışkan sıkıştırılamaz kabul edilmiştir. Son adım akış ortamına karar verilmesidir. Bu çalışmada bir hava alığından içeriye gönderilen hava, çok sayıdaki çıkış alıklarından dış ortama gönderildiği için akışımız bir iç akıştır.

\section{Materyal ve Metot}

\subsection{Tasarlanan Hull Yapısının Ansys Fluent ile Analizi}

\subsubsection{Geometrik Modelleme}

Analizi yapılacak olan geometri Solidworks CAD programında çizilmiştir. Güvertenin üst yüzeyi $5565 \mathrm{~mm}$ uzunluğunda ve $2350 \mathrm{~mm}$ genişliğindedir. Alt yüzey ise su yüzeyindeki hidrodinamik kuvveti minimize etmek amacıyla 30 derece açı verilerek $300 \mathrm{~mm}$ derinlik ile tasarlanmıştır. Orta bölümde yer alan oda havanın yönlendirilmesi amacıyla yerleştirilmiştir. Giriş hava alığının çapı $850 \mathrm{~mm}$ ve çıkış hava alıklarının çapları $130 \mathrm{~mm}$ olup 31 adettir.

\subsection{2. Çözüm Ağı Oluşturma}

Tablo 1'de verilen parametre ve koşullarla ANSYS FLUENT'te temel geometri modeli oluşturulmuştur. Seçilen parametreler geometrinin malzemesine akışkanın türüne ve sınır koşullarına dayanmaktadır. Element boyutları ve sayısı literatürde yapılmış olan çalışmalar göz önünde bulundurularak çözüm ağı oluşturulmuştur. Çok sayıda yazılım programı olmasına rağmen komplex ve gerçeğe en yakın sonuçları elde etmemizi sağlayan ANSYS FLUENT(HAD) programı seçilerek analizler yapılmıştır. Tablo 1'de kullanılan çözüm ağ modellemesinin verileri ve Şekil 3 'te çözüm ağı modellemesinin geometri üzerindeki uygulaması verilmiştir. $\mathrm{Bu}$ çerçevede kullanılan lisanslı yazılımın element sayısı limitinden kaynaklı olarak 494529 adet element ve 94966 adet düğüm oluşturulmuştur. Gerçeğe en yakın sonuçlar elde edilebilmesi için kullanabileceğimiz maksimum element sayısı budur. Geometrinin keskin yüzeyli yapısından dolayı en uygun ağ türü üçgen yapılıdır. 
Tablo 1. HAD Analizinde Kullanılan Koşulların Detayları.

\begin{tabular}{|l|l|}
\hline Materyal Türüi & Akışkan \\
\hline FLUENT Akışkan Materyalleri & Hava \\
\hline Yoğunluk & $1,225 \mathrm{~kg} / \mathrm{m}^{3}$ \\
\hline Viskozite & $1.7894 \mathrm{e}-05 \mathrm{~kg} / \mathrm{m}-\mathrm{s}$ \\
\hline Gövde Malzemesi & Alüminyum \\
\hline Hız & $22.22 \mathrm{~m} / \mathrm{s}$ \\
\hline Enerji Denklemi & Açık \\
\hline Düğüm & 94966 \\
\hline Element Sayısı & 494529 \\
\hline Cözüm Ağının Türüi & Üçgen \\
\hline
\end{tabular}

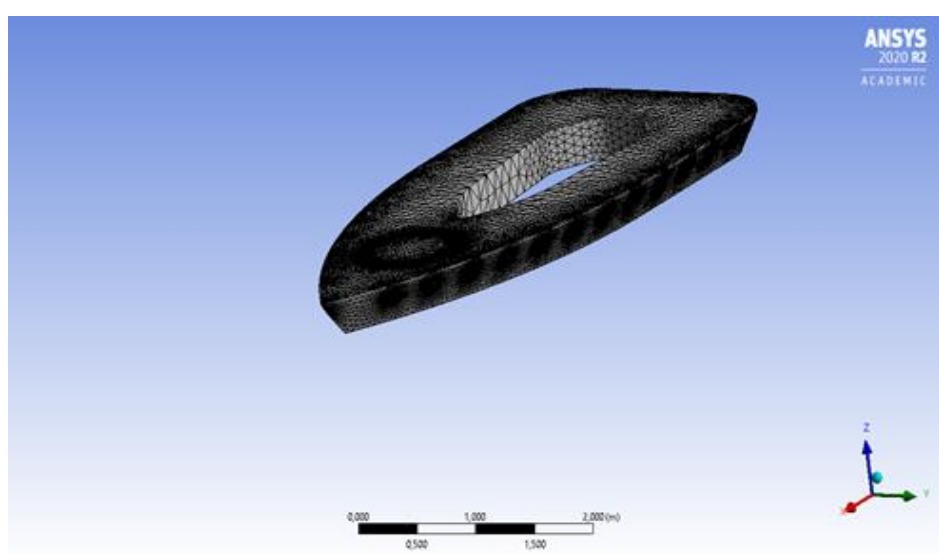

Şekil 3. Çözüm Ă̆̀.

\subsubsection{Sınır Koşullarının Belirlenmesi}

"Realizable k-E" modeli bir çift denklemli modeldir. Türbülans viskozitesindeki taşınım denklemini çözmek için iki ayrı denkleme sahiptir. k- $\varepsilon$ modeli düzlemsel kayma gerilmesi (planar shear stress) ve devir daim akışları (recirculating flows) için tasarlanmıştır. Bu model endüstriyel ve çevresel akışlar için oldukça geniş bir kullanım alanına sahiptir. Reynolds kayma gerilmelerinin en önemli yere sahip olduğu sınırlı akışlar (confined flows) ve küçük basınç gradyanlı serbest kayma tabakalı (free-shear layer) akışlar için oldukça kullanışlıdır. B.E. Launder ve D.B. Spalding tarafindan 1974 yılında ortaya atılmıştır. "Realizable k- $\varepsilon$ " türbülans modelinin denklemi aşağıda verilmiştir (Maples, Morse, Launder ve Spalding, 1974).

\subsubsection{Taşınım Denklemleri}

$\frac{\partial}{\partial t}(\rho k)+\frac{\partial}{\partial x_{j}} \quad\left(\rho k u_{j}\right)=\frac{\partial}{\partial x_{j}}\left[\left(\mu+\frac{\mu_{t}}{\sigma_{k}}\right) \frac{\partial k}{\partial x_{j}}\right]+P_{k}+P_{b}-\rho \in$

$-Y_{M}+S_{k}$

$\frac{\partial}{\partial_{t}}(\rho \epsilon)+\frac{\partial}{\partial x_{j}}\left(\rho \epsilon u_{j}\right)=\frac{\partial}{\partial x_{j}}\left[\left(\mu+\frac{\mu_{t}}{\sigma_{\varepsilon}}\right) \frac{\partial_{\varepsilon}}{\sigma_{\epsilon}}\right]+\rho C_{1} S_{\varepsilon}-$

$\rho C_{2} \frac{\varepsilon^{2}}{k+\sqrt{v \epsilon}}+C_{1 e} \frac{\epsilon}{k} C_{3 e} P_{b}+S_{e}$

Buradan

$C_{1}=\max \left[0.43, \frac{n}{n+5}\right], \quad n=S \frac{k}{\epsilon}, \quad S=\sqrt{2 S_{i j} S_{i j}}$

Bu denklemlerde hız gradyanları tarafindan üretilen türbülans kinetik enerjisinin ifadesidir. Standart k-e model ile aynı yoldan hesaplanır. $\mathrm{P}$ _b ise kaldırma kuvveti ile üretilen türbülans kinetik enerjisinin ifadesidir. Buda yine standart k-e model ile aynı yoldan hesaplanır.

Türbülans viskozitesinin modellenmesi:

$u_{t}=\rho C_{u} \frac{k^{2}}{\epsilon}$

Buradan

$$
\begin{aligned}
& C_{u}=\frac{1}{A_{0}+A_{8} \frac{k U^{\epsilon}}{\epsilon}} \\
& U^{*} \equiv \sqrt{S_{i j} S_{i j}+\widetilde{\Omega}_{i j} \widetilde{\Omega}_{i j}} \\
& \widetilde{\Omega}_{i j}=\Omega_{i j}-2 \epsilon_{i j k} \omega_{k} \\
& \Omega_{i j}=\Omega_{i j}-\epsilon_{i j k} \omega_{k}
\end{aligned}
$$

$A_{0}=4.04, \quad A_{s}=\sqrt{6} \cos \cos \emptyset$

$\emptyset=\frac{1}{3}(\sqrt{6} W), W=\frac{s_{i j} S_{j k} S_{k i}}{\tilde{S}^{3}}$,

$$
\tilde{S}=\sqrt{S_{i j} S_{i j}}, \quad S_{i j}=\frac{1}{2}\left(\frac{\partial u_{j}}{\partial x_{i}}+\frac{\partial u_{i}}{\partial x_{j}}\right)
$$

Modelin deneysel sabitleri:

$$
\mathrm{C}_{1 \epsilon}=1.44 C_{2}=1.9, \quad \sigma_{k}=1.0, \quad \sigma_{\epsilon}=1.2
$$

\subsection{5. İşlem Süreci}

Güvertenin üst kısmında hava alığına yerleştirilen fanın içeriye optimum hava üfleme hızı olan $22.22 \mathrm{~m} / \mathrm{s}$ ile hull bölgesine $0^{0}$ ile $30^{0}$ arasında hava üflenerek iç bölge hava ile doldurulmuştur. Doldurulan hava ile çıkış alıklarında oluşan ve sadece hava akışı ile oluşacak olan dinamik basınç, türbülans ve hız büyüklükleri gözlemlenerek optimum hava giriş açısı ve çıkış alıklarında oluşan dinamik basınç dağılımları, türbülans ve hız değerleri elde edilmeye çalışılmıştır. Bu süreçte deneylere en yakın değerleri elde etmemize olanak sağlayan basınç temelli "realizable k-e" standart Wall Functions matematiksel modellemesi seçilmiştir. Momentum Second Order Upwind ve referans değer ve başlangıç pozisyonu olarak giriş hava alığı değerleri alınmıştır. Analiz işlem süreci seçimleri aşağıdaki Tablo 2'de verilmiştir.

Tablo 2. Analiz seçim tablosu.

\begin{tabular}{|l|l|}
\hline Çözücū Seçimi & Basınç Temelli \\
\hline Matematiksel Model & Realizable k-e Standart wall functions \\
\hline Çözüm Kontrolleri & Gauss-Seidel Akış Türbülans Enerjisi \\
\hline Momentum & Second Order Upwind Scheme \\
\hline Başlatıcı Değerler & Giriş Değerleri \\
\hline Görüntülenen Güçler & Dİnamik Basınç, Türbülans Yoğunluğu \\
\hline Referans Değerler & Giriş Alığı Deǧerleri \\
\hline Yakınsama Sınırı & $1 \times 10^{-6}$ \\
\hline
\end{tabular}

\subsection{Gövde Tasarımı ve Analizi}

Yapılan analizler sonucunda en ideal hava giriș açısının 220 olduğu gözlenmiştir. Hull'un orta bölümüne yerleştirilen adacık yardımıyla hem iç bölgenin tamamen doldurulması için gereken hava hava miktarı düşürülmüş ve arka bölmede yer alan çıkış alıklarına hava yönlendirilmesi sağlanarak tüm hava çıkış alıklarında homojen ve minimum türbülanslı hava akışı sağlanmıştır.

Çıkış alıklarındaki dinamik basınç oluşumu, kontur grafiklerine bakıldığında gözükmektedir. Hull geometrisi sol taraftan önden arkaya olacak şekilde incelendiğinde tam 
manasıyla eşit olmasa da dinamik basınç oluşmuştur. Böylece aracın gövde altında oluşacak olan hava yastıklamasına basınçlı hava tedariği sağlanmıştır.(Bkz. Şekil 4) Şeklin boydan simetrik yapısı da göz önünde bulundurarak sağ taraftan önden arkaya çıkış alıklarında da dinamik basınç oluşumu gözlemlenmiş ve hava yastıklamaya basınçlı hava tedarik edilmiştir.(Bkz. Şekil 5)

Hull yapısının geometrik şekline bakıldığında en arkadaki çıkış alıklarında dinamik basınç oluşumu oldukça hassas bir konudur. Çünkü bu alıklar hem giriş alığına uzak hem de basınçlı akışkan buraya gelene kadar kademeli olarak sağ ve sol çıkış alıklarından basınç kaybı yaşamaktadır. Ancak yapılan çalışmada Hull yapısına arkadan baktığımızda giriș alığına belli bir açıyla hava yönlendirerek arkadaki beş adet alıkta dinamik basınç gözlemlenmiştir. Hoverwing aracını seyir halinde düşünecek olursak bu beş çıkış alığı denge açısından kritiktir çünkü aracın en arkasında oluşabilecek bir basınç düşümü aracın gövde altında oluşan hava yastıklamasının dengesiz hale gelmesine sebep olabilir. .(Bkz. Şekil 6)

Her çıkıș alığına basınçlı bir basınçlı hava gönderilerek yapı içerisindeki akışın sürekliliği sağlanmış ve iç yapıda herhangi bir türbülans ve ters akış oluşumu gözlemlenmemiştir. Türbülans yoğunluk vektör grafiğine bakıldığında vektör yoğunlaşmasının giriş alığının kenarında arttığı gözlemlenmiştir. Bunun sebebi giriş alığının keskin bir yapıda olmasıdır. Giriş alığına hava sağlayacak pervanenin kavis köşeli bağlantısı ile bu sorun giderilecek ve sistem açısından sorun teşkil etmeyecektir. Çıkış alıklarında oluşan girdap şeklindeki türbülans vektörleri ise yüksek basınçtan alçak basınca geçen havanın doğal sonucudur.(Bkz. Şekil 7)

ANSYS

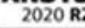

$\frac{2020 \mathrm{R2}}{\mathrm{ACADEMIC}}$

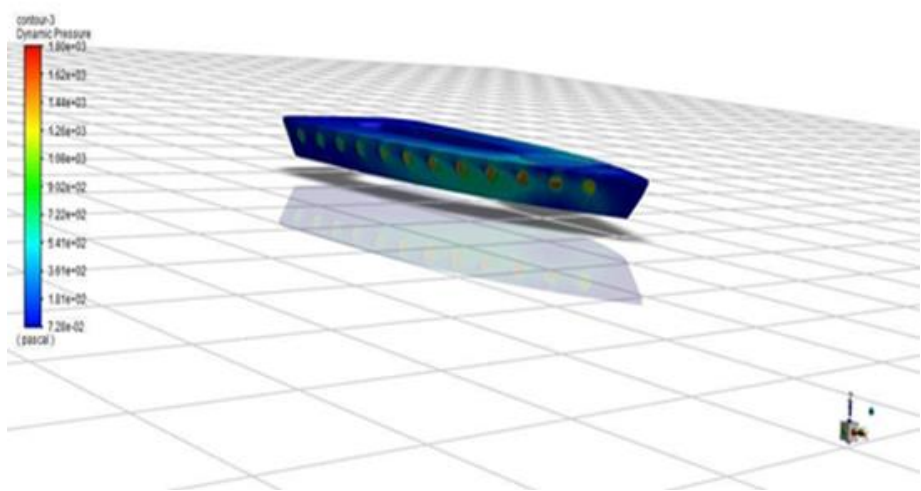

Şekil 4. Dinamik basınç konturu sol yan görünüş.

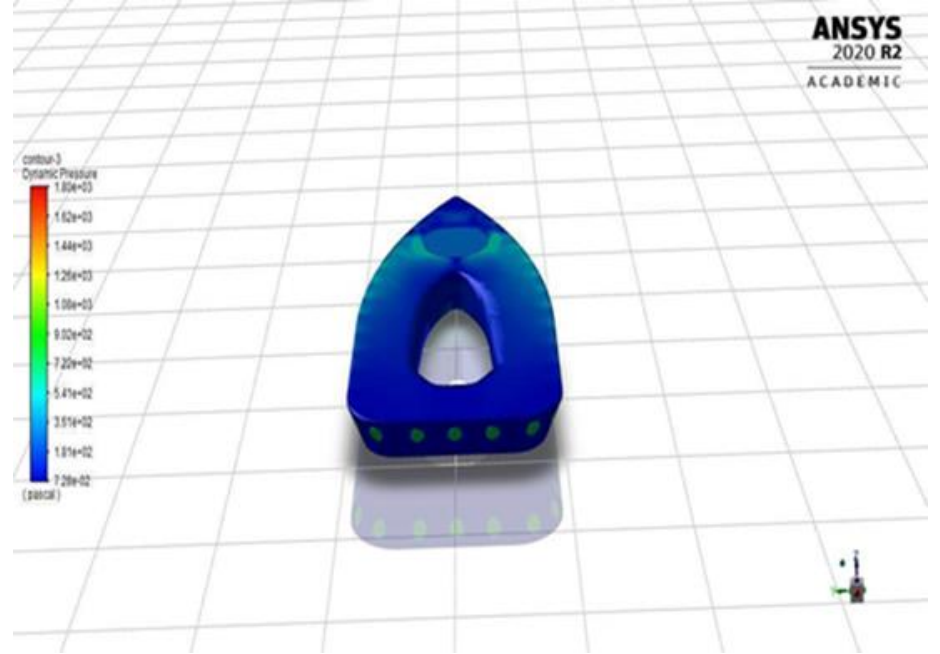

Şekil 5. Dinamik basınç konturu arka görünüş.

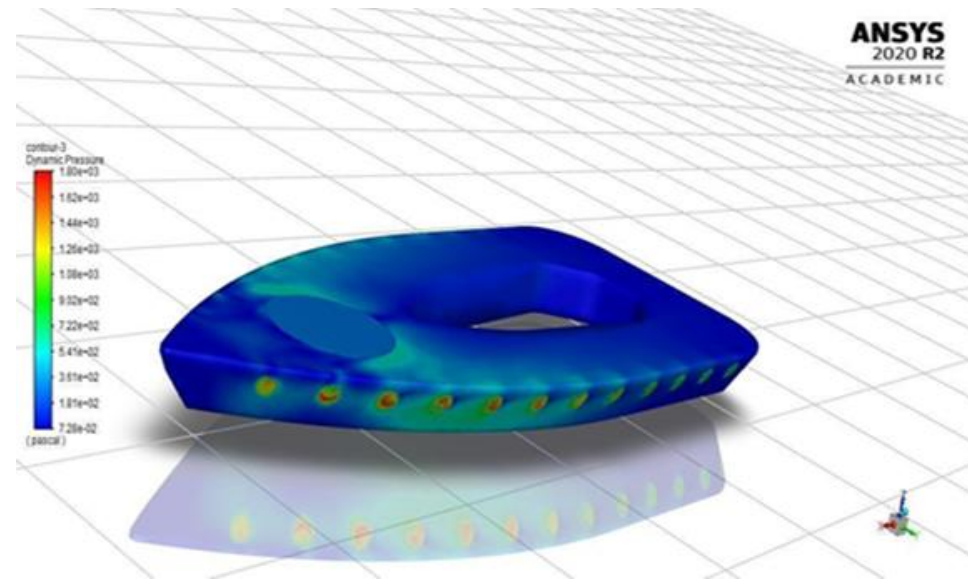

Şekil 6. Dinamik basınç konturu sağ yan görünüş.

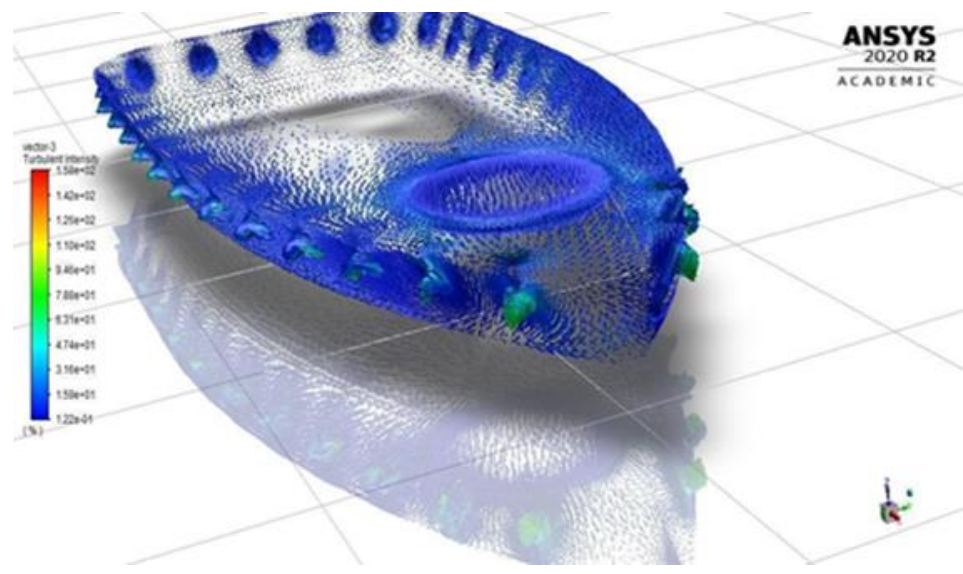

Şekil 7. Türbülans yoğunluk vektörleri.

\section{Sonuç}

$\mathrm{Bu}$ çalışmada gözlemlediğimiz üzere hull yapısının üzerindeki çıkıș alıklarınından tatmin edici bir hava çıkışı elde edebilmemiz için giriş alığından sağlanacak havanın giriş açısı hayati önem taşımaktadır. Aksi takdirde hull yapısının arka tarafında kalan çıkış alıklarında yeteri miktarda dinamik basınç elde edilemez ve aynı zamanda ön ve arka çıkış alıklarında oluşan basınç farkından dolayı dengesizliğe sebep olabilir. Hull yapısının yapısal ve fiziki özelliklerinden dolayı seçilen 
türbülans modellemesi "realizable k-e" olmuştur. Bu türbülans modellemesinde giriş alığına çeşitli açılarda açılarda belli değerlerde hava gönderilmiştir. Yapılan çeşitli analizler sonucunda optimum giriş alığı açısının $22^{0}$ olduğu saptanmıştır. Böylece istenildiği gibi her bir çıkış alığına dengesizlik yaratmayacak şekilde basınçlı hava sağlanmıştır.

İleriki çalışma olarak düşük ve yüksek dinamik basınca sahip çıkış alıklarının çapları değiştirilerek homojene en yakın değer elde etmek amacıyla, tüm alıklardan sabit dinamik basınç elde edilmesi için yeni analizler yapılabilir.

\section{Kaynakça}

Abele , G., \& Brown, J. (1977). Arctic transportation: operational and environmental evaluation of an Air Cushion Vehicle in Northern Alaska.

Akdemir, S., Öztürk, S., Edis, F. O., \& Ülger, P. (2012). Soğuk hava depolarında ortam koşullarının hesaplamalı akışkanlar dinamiği (CFD) ile modellenmesi. Tarım Makinaları Bilimi Dergisi, 241-248.

Bal, Ş. (2019). DEĞİŞKEN ENKESİTLİ AÇIK KANAL AKIMININ DENEYSEL VE SAYISAL MODELLEMESİ. http://acikerisim.harran.edu.tr:8080/jspui/bitstream/11513/2 067/1/555791.pdf adresinden alınd 1

Bhaskaran, R., \& Collins, L. (2002). Introduction to CFD basics. 1-21. Cornell University-Sibley School of Mechanical and Aerospace Engineering.

Broughton, K., Martin, D., Williams, D., \& Wunderlin, N. (2016). Multipurpose Off-road Flying Vehicle.

Durgawale, A. A., Raut, S. S., Suryawanshi, A. L., Patil, S. P., \& Mali, V. P. (2017). Design and Fabrication of Hovercraft. International Engineering Research Journal, 1-4.

Launder, B., \& Sharma, B. I. (1974). APPLICATION OF THE ENERGY-DISSIPATION MODEL OF TURBULENCE TO THE CALCULATION OF FLOW NEAR A SPINNING DISC. LETTERS IN HEAT AND MASS TRANSFER, 131138.

Okafor, B. (2013). Development of a Hovercraft Prototype. International Journal of Engineering Technologies, 276281.

Özcan, O., \& Kaya, K. (2013). A numerical investigation on aerodynamic characteristicsof an air-cushion vehicle. Journal of Wind Engineering and Industrial Aerodynamics, 70-80.

Paval, M. S., Popescu, A., Popescu, T., Zahariea, D., \& Husaru, D. E. (2018). Numerical study on the movement of air inside the inner cavity of a hovercraft model. IOP Conference Series: Materials Science and Engineering, (s. 1-10).

Spalding, D. B., Launder, B. E., Morse,, A. P., \& Maples, G. (1974). COMBUSTION OF HYDROGEN-AIR JETS IN LOCAL CHEMICAL EQUILIBRIUM.

Şahin , H. M., Dal, A. R., \& Özkaya, M. (2020). Numerical Analysis by RNG k- $\varepsilon$ Turbulent Model of a Concentric Tube Heat Exchanger with Coiled Wire Turbulator . Fen Bilimleri Dergisi, 64-78.
Tiwari, A. (2015). TO STUDY AND FABRICATION OF AIR CUSHION VEHICLE. INTERNATIONAL JOURNAL OF RESERACH, 70-84.

Tu, J., \& Yeoh, G. H. (2018). Computational Fluid Dynamics (A Practical Approach). Butterworth-Heinemann.

Xia, B., \& Sun, D.-W. (2002). Applications of computational fluid dynamics (CFD) in the food industry: a review. ELSEVIER, 5-24. 